\title{
Undergraduate Sport Management Education: Exploring Ego Development and Leadership Efficacy
}

\author{
Shannon Kerwin and Kirsty Spence \\ Brock University
}

\begin{abstract}
This research explored students' ego development and leadership efficacy during an undergraduate sport management program. A sequential mixed-method case study design and associated methodologies were adopted to explore students' ego development and leadership efficacy during 3 years of an academic program. Results show fluctuations in leadership efficacy for all but one participant. These fluctuations are discussed in relation to ego development in that growth from self-conforming to self-authoring stages of ego development may partially explain fluctuations in how students see themselves and their potential for leadership in the field of sport management. The role of the ego development construct in relation to students' perceptions of their leadership capabilities highlights that programmatic elements (e.g., thoughtful experiential education) can be consciously developed and strategically leveraged to more accurately target perceptions of leadership prowess among students. The findings emphasize that students' level of ego development can be fostered through active and effective program delivery.
\end{abstract}

Keywords: leader, mixed methods, student, vertical development

Sport management educators have been challenged to adopt more critical approaches to their educational programs (Cunningham, 2014; Shaw \& Frisby, 2006; Zakus et al., 2007). Specifically, Cunningham (2014) asserted that the current program offerings related to sport management concepts, internships, and placements are conservative in nature and have not been subjected to critical review. Furthermore, Shaw et al. (2011) argued that sport management educators need to adopt critical approaches that teach students how to question assumptions, challenge the status quo, and engage in transformative activities within their undergraduate experiences. Rather than producing "technicist administrators," Zakus et al. (2007) advocated for sport management educators to develop students' critical thinking toward innovative leadership.

Many sport management programs offer placements or internships that propose a unique developmental experience for students (Cunningham, 2014; Zakus et al., 2007). For these experiences to be meaningful for students' higher-level perceptions of self, however, a greater focus on experiential, personal, and professional development must be exerted within these offerings (Cunningham, 2014; DeLuca \& Braunstein-Minkove, 2016). If sport management programs do not include opportunities for students' explicit development, students will be substantially less likely to develop critical thinking skills and reflective capacity from experiential learning opportunities (Brown et al., 2018). Therefore, it is becoming increasingly relevant to explicitly investigate the developmental capacity for critical thinking that occurs among students within sport management programs. One way forward with such an investigation is with the construct known as ego development (Spence et al., 2009).

Spence et al. (2009) noted that sport management educators can design and administer undergraduate curricula focusing on

The authors are with the Dept. of Sport Management, Faculty of Applied Health Sciences, Brock University, St. Catharines, ON, Canada. Kerwin (skerwin@brocku. ca) is corresponding author. students' vertical development, thereby facilitating their perceptions of self and their leadership development. Cook-Greuter and Soulen (2007) defined vertical development as how individuals interpret and make meaning of their experiences in novel ways, leading to transformations in their reality, given "increases in what we are aware of, or what we can pay attention to, and, therefore, what we can influence and integrate" (p. 182). Vertical development is differentiated from horizontal or lateral development in which most adult developmental initiatives are designed, targeted, and documented (Cook-Greuter, 2013a). Horizontal development is defined as how individuals experience increases or expansions in their knowledge and skill base without fundamentally changing how they interpret or make meaning of their lives and experiences (Cook-Greuter \& Soulen, 2007). A sole focus on horizontal development within sport management academic programs may hinder leadership and development opportunities (Cunningham, 2014; Spence et al., 2009). Throughout this research, horizontal and lateral development terms are used interchangeably (CookGreuter, 2013a).

Theoretically, it is posited that how sport management students view themselves (self-efficacy) will fluctuate with their vertical development (or lack thereof), given the associated, transformative changes in one's meaning-making capacity-and, ultimately, the changes in one's reality - with such development. For sport management educators, understanding how students make meaning and conceive reality, in relation to their view of themselves as they initially enter and leave an academic undergraduate program upon graduating, creates the potential to develop curricula targeted toward students' vertical development and the development of their self-efficacy and themselves as leaders. This focus on development is a "crucial" undertaking, considering "the complexity and interconnected nature of the business environment and subsequent shift from technical to adaptive challenges" (McDonald $\&$ Spence, 2016, p. 146). Furthermore, exploring such potential serves the call by Shaw et al. (2011), who emphasized the need to design and manage programs that explicitly address critical 
thinking and development. Finally, such efforts are increasingly relevant within an industry where calls to action for social change (e.g., \#MeToo, \#BLM and anti-racism education, sexual misconduct) require leadership from individuals who have engaged in vertical development.

The purpose of this research is to assess students' ego (vertical) development and leadership efficacy (LE) perceptions as they progress through an undergraduate sport management program. The manuscript addresses two research questions. First, how do undergraduate students' perceptions of LE fluctuate during the course of their sport management academic program? Second, how does undergraduate students' level of ego development connect with their perceptions of LE in a sport management academic program? Using a case study sequential mixed-method design for this empirical assessment, the utility of this research to the sport management education literature is two-fold. First, while the relationship between level of ego development and LE is theoretically sound, an empirical assessment of this relationship has yet to be conducted in the education literature, therefore filling a necessary gap in the literature. Second, this research provides an opportunity to assess undergraduate students' ego development and their perceptions of LE during a salient time of students' critical learning and development. Specifically, as McDonald and Spence (2016) contended, the context of the sport industry is one in which university educators may intuitively connect experiential education opportunities with social awareness challenges and complex learning environments. However, the extent to which students' ego development occurs within a sport management program broadly, and, within experiential education, more specifically, is relatively unknown.

\section{Theoretical Frameworks}

\section{Leadership Efficacy}

Perceptions of leadership are vital in determining one's ambition for leadership or managerial positions (McCormick et al., 2002). These researchers recognized that while not every student desires a leadership position within a chosen career path, their "belief-inself" toward their ability to succeed in leadership positions provides important information regarding the perception of self a student gains (or loses) while completing an undergraduate degree (McCormick et al., 2002). As such, LE is an important construct to explore when identifying development within a sport management program. Specifically, LE is a concept derived from self-efficacy and refers to one's "belief in their capability to lead others and fulfill whatever roles necessary in that capacity" (Quigley, 2013, p. 580).

Quigley (2013) found that students' perceptions of their leadership capability and intentions develop during their academic and professional careers. Ultimately, as students become increasingly aware of their leadership capabilities, the perceptions of the kinds of environments that may lend to their leadership effectiveness also broaden (Quigley, 2013). Furthermore, students' perceptions differ over time and are dependent upon individual personality factors (i.e., emotional stability, agreeableness, openness to experience). Quigley (2013) also noted that when credible sources (e.g., faculty) provide students with performance feedback, their self-efficacy related to their leadership capability increases - a finding that supported Hannah et al.'s (2008) notion that external factors impact perceptions of self, related to one's leadership.
To emphasize a perception of belonging, DeWitz et al. (2009) discussed the importance of self-efficacy among undergraduate students, highlighting that many factors (e.g., support, motivation, academic performance) contribute to changes in students' self-efficacy within this critical stage of development. In sport management programs, though Williams and Parker (2016) discussed increased ratings of students' self-efficacy once engaged in an experiential education project, relatively little is known about the nature of programmatic components that contribute to efficacy in students related to these experiences. Brown et al. (2018) emphasized the need to critically review sport management programs to understand if and where development occurs. Although DeWitz et al.'s (2009) and Williams and Parker's (2016) findings are interesting and lend support to nuances within self-efficacy for undergraduate students, scant research exists that examines the theoretical and empirical mechanisms that underlie the vertical development of sport management student (i.e., undergraduate, graduate) populations.

\section{Ego Development and the Leadership Development Framework}

Human behavior is the result of the continuous reciprocal interaction of cognitive, behavioral, emotional, and environmental influences (Bandura, 1977). Thus, one's worldview may influence what they observe and pay attention to (attention), what information they retain (retention), and how they reproduce that observation (reproduction), all of which lead to one's self-efficacy. One such mechanism that furthers theoretical understanding around the development of one's worldview that may influence LE is the construct of ego development. Loevinger (1979) conceived ego development as incorporating, first, the complexity of one's moral judgment; second, the nature of how one engages in interpersonal relations; and, third, the context for which one perceives one's self and others. Cook-Greuter (1994) additionally suggested that ego development represents the interconnection of one's selfconception and conception of reality.

The ego development construct is conceptualized further into seven specific vertically oriented levels or stages within the Leadership Development Framework (LDF), a structural, stagespecific model wherein each level of ego development is known as an action logic and is linked to specific and distinct characteristics related to an individual's degree of leadership effectiveness (CookGreuter, \& Soulen 2007; Fisher et al., 2003; Rooke \& Torbert, 2005). Each action logic is composed of three interrelated components: first, a functional or behavioral component, where one's behaviors are displayed per their purpose, needs, and intentions; second, an affective component, associated with one's emotions and experience of interacting within the world; and, third, a cognitive component, related to how one alters his or her thinking to make sense of or find meaning in experiences.

These three interrelated components form "a synthesis of doing, being, and thinking despite the term logic, which may suggest an emphasis on cognition" (Cook-Greuter, 2013a, p. 13). Stages of ego development are referred to as action logics because the stages emphasize "how professionals tend to reason and behave in response to their experience" (Cook-Greuter, 2004, p. 278). Furthermore, the three action logic components interrelate around associated unique sets of cognitive, psychosexual, psychosocial, and moral characteristics (McCrae \& Costa, 1980). To serve the purpose and adhere to common practice within ego development literature as it relates to leadership effectiveness (CookGreuter, 2004; Rooke \& Torbert, 2005), the terms related to levels 
or stages and ego development or action logic are used interchangeably throughout this manuscript.

In Table 1, the seven LDF action logics and associated characteristics are outlined (Fisher et al., 2003). Rather than noting these LDF action logics as a hierarchy, each progressively vertically oriented action logic may be viewed as representing one's movement toward increasingly differentiated development, with associated increasing complexity related to cognitive, emotional, and behavioral capacities linked to leadership skills and processes. For example, while an Expert individual may possess conforming behaviors insofar as aligning with reliable and trusted "Expert" authorities and seeking direction from respected and credible others, as they vertically develop to the Achiever action logic, they will adopt self-authoring behaviors insofar as developing a personal agenda and taking a stand for what they believe in and giving a voice to such beliefs, while maintaining respect and appreciation for those in authority positions (Cook-Greuter, 2013a).

Research on ego development scores of undergraduate and graduate student samples indicates a rank distribution of Experts, followed by Achievers and then by Diplomats (Adams \& Shea, 1979; Lambie et al., 2010)—findings similar to managerial samples (Cook-Greuter, 2004; Rooke \& Torbert, 2005). Thus, it is increasingly relevant to examine vertical development generally and LDF action logic stage-related transitions specifically among undergraduate student populations, given the representative developmental pathway such that individuals who exhibit group-conforming (Diplomat) behaviors may vertically develop over time to exhibit self-conforming (Expert) behaviors and then again may vertically develop to exhibit self-authoring (Achiever) behaviors, which may provide a theoretical explanation for LE variation among such students within an academic program. Such an exploration serves the call for greater understanding regarding how development is critically assessed and adopted within sport management programs (e.g., Cunningham, 2014; McDonald \& Spence, 2016; Shaw et al., 2011; Spence et al., 2009).

\section{Methodology}

\section{Design}

A longitudinal sequential QUANT-QUAL mixed-method case study design (Creswell et al., 2003) was adopted, such that quantitative surveys assessing participants' LE perceptions and their ego development served as a baseline for analysis and discussion related to qualitative interviews assessing participants' perceptions of self as related to leadership and their ego development within an undergraduate sport management student sample during a 3-year period. Within a QUANT-QUAL mixed-method case study design, Creswell (2009) noted that researchers need not focus on statistically significant changes in the quantitative data; rather, in the current study, it was acceptable to focus on analyzing fluctuations in the descriptive and variation statistics to highlight areas of emphasis for follow-up with each participant during the qualitative collection and analysis phases.

Case study methodology was adopted as a means to theoretically contribute to knowledge based on the selection of a case (e.g., one undergraduate sport management program) that possesses specific characteristics (e.g., male-dominated student population, theoretical and practical components of course content, emphasis on experiential education, explicit program marketing of leadership development) that may be transferred to other such cases/programs. All participants experienced these facets of the program throughout the 3-year longitudinal duration of the research. These characteristics represent the boundary of the case in which the participants functioned. The case is appropriate given the

\section{Table 1 Managerial Style Characteristics of Seven Leadership Development Framework Action Logics}

\begin{tabular}{|c|c|}
\hline Frame & Managerial style characteristics \\
\hline $\begin{array}{l}\text { Opportunist } \\
\text { Stage } \Delta\end{array}$ & $\begin{array}{l}\text { Short time horizon; focuses on concrete things; manipulative; deceptive; rejects feedback; externalizes blame; distrustful; fragile self- } \\
\text { control; hostile humor; views luck as central; flouts power and sexuality; stereotypes; views rules as loss of freedom; punishes } \\
\text { accordingly to "eye for an eye" ethic; treats what can get away with as legal; forcibly self-interested. }\end{array}$ \\
\hline $\begin{array}{l}\text { Diplomat } \\
\text { Stage } \Delta / 3 ; \text { Stage } \\
3\end{array}$ & $\begin{array}{l}\text { Observes protocol; avoids inner and outer conflict; works to group standards; speaks in clichés and platitudes; conforms; feels shame } \\
\text { if violates norms; feels bad hurting others; receives disapproval as punishment; seeks membership and status; face-saving essential; } \\
\text { loyalty to immediate group, not "distant" organization or principles; needs acceptance. }\end{array}$ \\
\hline $\begin{array}{l}\text { Expert } \\
\text { Stage } 3 / 4\end{array}$ & $\begin{array}{l}\text { Interested in problem-solving; seeks causes; critical of self and others based on craft logic; chooses efficiency over effectiveness; } \\
\text { continuous improvement and perfection; accepts feedback only from "objective" craft masters; dogmatic; values decisions based on } \\
\text { merit; sees contingencies, exceptions, wants to stand out, be unique; sense of obligation to wider, internally consistent moral order. }\end{array}$ \\
\hline $\begin{array}{l}\text { Achiever } \\
\text { Stage } 4\end{array}$ & $\begin{array}{l}\text { Longer-term goals; future is vivid and important; welcomes behavioral feedback; effectiveness and results oriented; feels like an } \\
\text { initiator, not pawn; appreciates complexity and systems; seeks generalizable reasons for action; seeks some mutuality (as well as } \\
\text { hierarchy) in relationships; feels guilt if does not meet own standards, blind to own achieving shadow, to the subjectivity behind } \\
\text { objectivity; energized by practical day-to-day improvements based on self-chosen (but not self-created) ethical system. }\end{array}$ \\
\hline $\begin{array}{l}\text { Individualist } \\
\text { Stage } 4 / 5\end{array}$ & $\begin{array}{l}\text { Works independently with a high value on individuality; self-curious; freer of obligation and imposed objectives, thus finds new } \\
\text { creativity; aware that what one sees depends upon one's world view and experiments with this; may be a maverick as they experiment } \\
\text { with finding their own way; uses power differently; increasingly conscious of the impact they have. }\end{array}$ \\
\hline $\begin{array}{l}\text { Strategist } \\
\text { Stage } 5\end{array}$ & $\begin{array}{l}\text { Creative at conflict resolution; recognizes importance of principles, contracts, theories, and judgments—not just rules, customs, and } \\
\text { exceptions-for making and maintaining good decisions; process oriented as well as goal oriented; aware of paradox and } \\
\text { contradiction, unique market niches, and particular historical moments; relativistic; enjoys playing a variety of roles; witty, existential } \\
\text { humor (as contrasted to prefabricated jokes); aware of dark side, of profundity of evil, and is tempted by its power. }\end{array}$ \\
\hline $\begin{array}{l}\text { Magician/ } \\
\text { Alchemist } \\
\text { Stage } 5 / 6\end{array}$ & $\begin{array}{l}\text { Disintegration of ego identity, often because of near-death experience; seeks participation in historical/spiritual transformations; } \\
\text { creator of mythical events that reframe situations; anchoring in inclusive present, seeing light and dark, order and mess; blends } \\
\text { opposites, creating "positive-sum" games; exercises own attention, researches interplay of intuition, thought, action, and effects on } \\
\text { outside world; treats time and events as symbolic, analogical, and metaphorical (not merely linear, digital, and literal). }\end{array}$ \\
\hline
\end{tabular}

Note. Adapted from Personal and Organizational Transformations: Through Action Inquiry (4th ed., p. 43), by D. Fisher, D. Rooke, and W.R. Torbert. Boston, MA: Edge/ Work. () 2003. 
need to understand how perceptions of leadership development are experienced in sport management programs where experiential education and leadership are marketed as key pillars for entering the program.

The single-case case study design was used to explore both the variation in students' ego development and LE scores and the influence of their ego development on LE perceptions within a single undergraduate program of study. A case may be chosen to extend emergent theory and provide a baseline for theoretical development in an area of inquiry (Eisenhardt, 1989). For this research, the case was the academic sport management program for which students were implicitly told (i.e., within course contexts, networking events, and informal or formal mentorship-oriented conversations) that they will develop leadership skills to enhance their chances of being leaders in the sport industry. Moreover, such messages are explicitly conveyed through recruitment tactics, often accompanied by visual representation and verbal messaging from current students and alumni. Serving the call by Shaw et al. (2011), the study was designed to explore student experiences within the case to assess fluctuations in both LE and ego development constructs, specifically related to programmatic components (e.g., courses and experiential opportunities).

To serve both the purpose and the sequential QUANTQUAL mixed-method case study design, participants completed an online survey assessing their LE perceptions in the first semester of their first (freshman) year, as well as their first and second semesters of their second (sophomore) and third (junior) years of academic study ( $N=5$ time points over 3 years). Participants also completed pencil and paper surveys assessing ego development in the second semester of their first (freshman), second (sophomore), and third (junior) years of academic study $(N=3$ time points). Following their third year of academic study, participants were interviewed and asked to reflect on events that occurred during 3 years within the program that they perceived affected their vertical development and LE perceptions (i.e., differing LE scores). Participants were explicitly asked questions to reflect on their program, courses, instructors, and experiential education opportunities that reflected theoretical tenets of these two constructs.

\section{Participants}

The sample case study population included students enrolled in the first year of an undergraduate sport management program ( $N=228$ students as majors). Within the recruitment process, a total of 69 individuals agreed to participate in the first-year survey regarding perceptions of LE. However, 15 students provided further and ongoing consent over 3 years thereafter to participate in the longitudinal study exploring LE and ED. The longitudinal process included completing an online LE survey and a reliable and valid pencil and paper ego development measure of ego development called the Washington University Sentence Completion Test (SCT; Loevinger, 1998; Manners \& Durkin, 2001) at multiple time points. During their third year of study, participants engaged in an interview during which they were asked to reflect on events that occurred during their first 3 years in the program. Students were asked to comment on courses, instructors, and experiential education components. At the end of the second year, one student dropped out of the study due to time constraints, leaving 14 participants remaining at the end of the 3-year study.

\section{Measures}

Survey Instrument. To provide foundational knowledge of if and how students' LE fluctuates across an undergraduate program, survey data were collected to measure LE among the sample population, thereby partially serving the first research question. First, participants were sent a link to an online survey at five time points (i.e., T1 in their first year [freshmen], T2 at the beginning of their second year [sophomore], T3 at the end of their second year, $\mathrm{T} 4$ at the beginning of their third year [junior], and T5 at the end of their third year), where they ranked their answers to 13 statements on a 5-point Likert scale, ranging from 1 (strongly disagree) to 5 (strongly agree) to measure their self-efficacy related to leadership intention and capability. To date, Quigley's (2013) definition of LE has not been operationalized. To serve the purpose of the study, items on the survey measuring LE were adapted from previously established and reliable measures and related to (a) belief in ability to obtain a leadership position (LE1) and (b) belief in possession of leadership capabilities (LE2).

Specifically, five items were adapted from Cunningham et al.'s (2005) study to measure students' capability judgments relating to the acquisition of, and performance in, leadership positions. In addition, eight items were adapted from McCormick et al.'s (2002) research to measure students' capability judgments relating to possessing specific leadership abilities. Second, to provide the empirical foundation to answer the second research question, participants completed the sentences to 36 sentence stem prompts comprising the SCT to measure their level of ego development (and commensurate LDF action logic; Loevinger, 1998; Manners \& Durkin, 2001) over three time points, including: T1 end of first year (freshmen); T2 end of second year (sophomore); and T3 end of third year (junior).

Interview Guide. To answer both research questions, semistructured interviews were developed and structured in three sections, with questions integrating previous literature outlining factors influencing ego development and LE (Cook-Greuter, 2004, 2013a; Quigley, 2013). These interviews were conducted with each participant after their third year of academic study, ranging between 25 and 46 min in length. In the first section, questions were developed with the intention that participants' responses would provide some insight into their level of ego development. In the second section, participants were asked specific questions directly regarding their SCT measures from Years 1, 2, and 3. Here, each student was sent, via e-mail, their ego development scores; a reading on specific levels of ego development and associated characteristics; and a summary table with descriptions of each stage of ego development, all prior to their respective interview. Participants were asked to discuss if they agreed with the level (and the description) for which they scored and to explain any perceived rationale further explaining developmental increases, plateaus, or regressions found occurring over the three (SCT) time periods. Participants were also asked to reflect on programmatic components that may have led to their vertical development score and commensurate action logic (e.g., courses, instructors, experiential education). In the third section, participants were sent their LE scores over five time points and were asked to discuss factors that may have caused LE score increases and decreases (Quigley, 2013). Again, participants were asked to reflect on programmatic components that may have led to fluctuations in LE scores (e.g., courses, instructors, experiential education). The definition of LE was based on participant interpretation of their LE scores within the survey measure and their perception of their ability to 
obtain a leadership position. Finally, where applicable, participants were asked to comment on LE development that had plateaued. In addition to understanding factors that may have influenced participants' self-perceptions, these responses were used to assess if participants' ego development may have contributed to their LE perceptions. The first interview was used as a guide, where specific minor edits were made to the guide for the next interviews to improve participant understanding of interview questions. A copy of the interview guide has been added as an Appendix.

\section{Analyses}

First, mean and $S D$ scores were calculated to determine participants' LE perceptions and were assessed to determine where fluctuations had occurred for each participant across five time points of data collection. These statistics were primarily used through the sequential QUANT-QUAL mixed-method case study design to identify fluctuations that could be further assessed and triangulated with qualitative interview findings (Creswell, 2009). Second, the researchers contracted a certified scorer who assessed each participant's 36 SCT sentence stems per a master scoring manual (Hy \& Loevinger, 1996) at each successive time point (i.e., Years 1, 2, and 3 of the academic program) to partially serve the second research question. The scorer calculated the distribution of assessed stem scores to yield a Total Weighted Score, which, in turn, led to a final Total Protocol Rating (TPR), from which a commensurate stage of ego development and LDF action logic (leadership) characteristics could be ascribed, per past scholarly work related to ego development and leadership effectiveness (Cook-Greuter, 2013a; Hy \& Loevinger, 1996; Rooke \& Torbert, 2005).

Third, to provide comprehensive responses to the two research questions and to extend the mixed-method design tenets, the researchers undertook inductive analysis using the interview guide as a framework to begin coding. Specifically, the researchers coded raw data line by line within interview transcripts, noting all emergent themes. After independently coding these data, the researchers created a respective in-depth summary table of coding trees and themes, at which time any discrepant coding schemes were shared and discussed between the researchers until a consensus was reached (Patton, 2014). These coding trees related to sections of text that reflected LE and ego development outlined by participants. The codes were separated by programmatic and nonprogrammatic "branches," referred to as child nodes (Patton, 2014). The researchers followed this process to both ensure intercoder trustworthiness and to use each other's respective coding trees and schemes as a comparison point for further clarification of findings. Following the researchers' initial coding of interview data, to answer the research questions, codes were collapsed into themes such that the researchers could further identify parent themes based on LE and levels of ego development (Patton, 2014).

Specific to the first research question, terms were coded related to participants' perceptions of how and why LE scores fluctuated across 3 years. In the context of this research, fluctuation refers to change, especially continuously and between one level or thing and another (Cambridge, 2020). For example, participants may have discussed gradual decreases, followed by increases in their perception of self, related to leadership. Participants attributed perceived increases to growing confidence based on their degree of experience in the sport industry. References to programmatic components were explicitly sought out within the analysis; however, very few were acknowledged by participants. Specific to the second research question, common codes were identified related to participants whose level of ego development remained changed over time; participants whose level of ego development both vertically increased and then regressed over time; and those whose level of ego development vertically increased to the next level. The parent themes then linked these codes to participants' perceptions of their LE.

\section{Findings}

The 14 participants involved in the longitudinal study were an average age of 20 years old, where five identified as women and nine identified as men (i.e., the sample ratio of female to male participants was proportionately higher than the gender composition within the academic program under study). Furthermore, all participants had transitioned to the program directly from graduating secondary school, $46 \%$ had been employed part time prior to entering the undergraduate program, $88 \%$ possessed previous volunteer experience, and $59 \%$ had accrued prior experience in a leadership position (e.g., coach, organizational manager role). Many of the students who enrolled in the program (case) typically came from sport backgrounds where they had gained experience within leadership positions on and off the field of play. Specifically, all 14 participants indicated they had engaged as athletes in high school, and 10 of the 14 participants had held captain positions on respective athletic teams, experiences that had bridged their leadership perceptions from high school to university. When asked, each of the 14 participants indicated that they indeed intended to be leaders in the sport management industry. This finding is not surprising, given both the marketing messages program educators and administrators emphasize and the initiatives in which they develop and showcase leadership positions in the field to recruiting students.

\section{Fluctuations in Perceptions of LE}

To answer the first research question, data indicated that LE was not a stable construct for participants, given how they perceived their LE to fluctuate during the first 3 years as they progressed through the context of this sport management program. For 13 of 14 participants, LE scores fluctuated uniquely over five time points, where, Jack, one of the 14 participants, scored the same at all five time points on all LE measures. In Table 2, the mean and $S D$ for each participant are highlighted at each of the five time points.

Participants' mean scores on LE1 items (i.e., participants' perceptions of their ability to obtain a leadership position) and LE2 items (i.e., participants' perceptions of their skilled ability to be a leader) were explored for trends in variation. While each participant's respective time series profiles on both LE1 and LE2 items were comparatively unique and variable, three trends were evident with respect to participants' profiles over five time points. A first trend revealed that participants' initial lower score on LE1 and LE2 items gives way to higher scores with subsequent fluctuating or plateaued measures. A second trend revealed participants' initial higher score on LE1 and LE2 items gives way to lower scores with subsequent fluctuating measures. A third trend revealed participants' similar scores on both LE1 and LE2 items through all measures, indicating plateaued scores across the five time points. While each of these trends were respectively seen across LE1 And LE2 items, participant profiles differed uniquely from each other for these constructs (i.e., for both LE scores and occurrence of 
Table 2 Participant LE Scores Across Five Time Points

\begin{tabular}{|c|c|c|c|c|c|}
\hline \multirow[b]{3}{*}{ Participant } & \multirow[b]{3}{*}{ Time point } & \multicolumn{4}{|c|}{ Descriptive and variation statistics } \\
\hline & & \multicolumn{2}{|c|}{ Leadership efficacy 1} & \multicolumn{2}{|c|}{ Leadership efficacy 2} \\
\hline & & M & $S D$ & $M$ & $S D$ \\
\hline \multirow[t]{5}{*}{ Bobby } & $\mathrm{T} 1$ & 3.80 & 0.84 & 3.50 & 0.93 \\
\hline & $\mathrm{T} 2$ & 3.80 & 0.45 & 3.88 & 0.83 \\
\hline & $\mathrm{T} 3$ & 4.20 & 0.45 & 4.00 & 0.60 \\
\hline & $\mathrm{T} 4$ & 4.20 & 0.45 & 4.06 & 0.86 \\
\hline & T5 & 4.00 & 0.71 & 4.40 & 0.73 \\
\hline \multirow[t]{5}{*}{ Steven } & $\mathrm{T} 1$ & 4.20 & 0.45 & 4.13 & 0.35 \\
\hline & $\mathrm{T} 2$ & 5.00 & 0.00 & 4.50 & 0.76 \\
\hline & $\mathrm{T} 3$ & 4.60 & 0.55 & 4.13 & 0.64 \\
\hline & $\mathrm{T} 4$ & 4.40 & 0.55 & 4.25 & 0.46 \\
\hline & $\mathrm{T} 5$ & 4.20 & 0.45 & 4.13 & 0.35 \\
\hline \multirow[t]{5}{*}{ Molly } & $\mathrm{T} 1$ & 4.60 & 0.55 & 4.63 & 0.52 \\
\hline & $\mathrm{T} 2$ & 5.00 & 0.00 & 4.00 & 0.53 \\
\hline & $\mathrm{T} 3$ & 5.00 & 0.00 & 4.50 & 0.53 \\
\hline & $\mathrm{T} 4$ & 4.80 & 0.45 & 4.38 & 0.52 \\
\hline & $\mathrm{T} 5$ & 4.60 & 0.55 & 4.25 & 0.46 \\
\hline \multirow[t]{5}{*}{ Ella } & $\mathrm{T} 1$ & 3.80 & 0.45 & 3.75 & 0.46 \\
\hline & $\mathrm{T} 2$ & 3.80 & 0.45 & 3.75 & 0.46 \\
\hline & $\mathrm{T} 3$ & 4.00 & 0.00 & 3.75 & 0.46 \\
\hline & $\mathrm{T} 4$ & 4.00 & 0.00 & 3.63 & 0.74 \\
\hline & $\mathrm{T} 5$ & 4.40 & 0.55 & 3.63 & 0.52 \\
\hline \multirow[t]{5}{*}{ Fadila } & $\mathrm{T} 1$ & 4.40 & 0.55 & 4.25 & 0.71 \\
\hline & $\mathrm{T} 2$ & 5.00 & 0.00 & 4.75 & 0.46 \\
\hline & $\mathrm{T} 3$ & 5.00 & 0.00 & 4.50 & 0.53 \\
\hline & $\mathrm{T} 4$ & 5.00 & 0.00 & 4.38 & 0.74 \\
\hline & $\mathrm{T} 5$ & 5.00 & 0.00 & 4.50 & 0.53 \\
\hline \multirow[t]{5}{*}{ Dan } & $\mathrm{T} 1$ & 5.00 & 0.00 & 4.38 & 0.52 \\
\hline & $\mathrm{T} 2$ & 5.00 & 0.00 & 4.38 & 0.52 \\
\hline & $\mathrm{T} 3$ & 4.60 & 0.55 & 4.38 & 0.74 \\
\hline & $\mathrm{T} 4$ & 5.00 & 0.00 & 4.38 & 0.52 \\
\hline & $\mathrm{T} 5$ & 5.00 & 0.00 & 4.25 & 0.46 \\
\hline \multirow[t]{5}{*}{ Katherine } & $\mathrm{T} 1$ & 4.00 & 0.00 & 3.38 & 0.74 \\
\hline & $\mathrm{T} 2$ & 4.00 & 0.00 & 3.50 & 0.53 \\
\hline & $\mathrm{T} 3$ & 4.80 & 0.45 & 3.88 & 0.64 \\
\hline & $\mathrm{T} 4$ & 4.40 & 0.55 & 3.88 & 0.35 \\
\hline & $\mathrm{T} 5$ & 5.00 & 0.00 & 3.88 & 0.64 \\
\hline \multirow[t]{5}{*}{ Adam } & $\mathrm{T} 1$ & 4.80 & 0.45 & 4.38 & 0.52 \\
\hline & $\mathrm{T} 2$ & 3.00 & 1.58 & 3.35 & 1.29 \\
\hline & $\mathrm{T} 3$ & 5.00 & 0.00 & 4.13 & 0.83 \\
\hline & $\mathrm{T} 4$ & 4.80 & 0.45 & 4.13 & 0.83 \\
\hline & $\mathrm{T} 5$ & 4.60 & 0.55 & 4.13 & 0.83 \\
\hline \multirow[t]{5}{*}{ Samantha } & $\mathrm{T} 1$ & 4.00 & 0.71 & 3.38 & 0.52 \\
\hline & $\mathrm{T} 2$ & 3.40 & 1.14 & 3.08 & 1.21 \\
\hline & $\mathrm{T} 3$ & 3.80 & 0.45 & 3.75 & 0.71 \\
\hline & $\mathrm{T} 4$ & 4.00 & 0.71 & 4.13 & 0.64 \\
\hline & $\mathrm{T} 5$ & 4.80 & 0.45 & 4.00 & 0.00 \\
\hline \multirow[t]{2}{*}{ James } & $\mathrm{T} 1$ & 3.20 & 0.45 & 3.50 & 0.53 \\
\hline & $\mathrm{T} 2$ & 3.60 & 1.14 & 3.07 & 1.20 \\
\hline
\end{tabular}


Table 2 (continued)

\begin{tabular}{|c|c|c|c|c|c|}
\hline \multirow[b]{3}{*}{ Participant } & \multirow[b]{3}{*}{ Time point } & \multicolumn{4}{|c|}{ Descriptive and variation statistics } \\
\hline & & \multicolumn{2}{|c|}{ Leadership efficacy 1} & \multicolumn{2}{|c|}{ Leadership efficacy 2} \\
\hline & & $M$ & $S D$ & $M$ & $S D$ \\
\hline & $\mathrm{T} 3$ & 4.20 & 0.45 & 3.48 & 0.51 \\
\hline & $\mathrm{T} 4$ & 4.20 & 0.45 & 4.00 & 0.76 \\
\hline & $\mathrm{T} 5$ & 4.20 & 0.45 & 3.88 & 0.83 \\
\hline \multirow[t]{5}{*}{ Brian } & $\mathrm{T} 1$ & 5.00 & 0.00 & 4.38 & 0.52 \\
\hline & $\mathrm{T} 2$ & 4.40 & 0.55 & 4.38 & 0.74 \\
\hline & $\mathrm{T} 3$ & 4.60 & 0.55 & 4.38 & 0.52 \\
\hline & $\mathrm{T} 4$ & 4.80 & 0.45 & 4.63 & 0.52 \\
\hline & T5 & 4.80 & 0.45 & 4.50 & 0.53 \\
\hline \multirow[t]{5}{*}{ John } & $\mathrm{T} 1$ & 3.20 & 0.45 & 3.25 & 0.71 \\
\hline & $\mathrm{T} 2$ & 3.60 & 0.55 & 3.50 & 0.53 \\
\hline & T3 & 3.80 & 0.45 & 3.50 & 0.53 \\
\hline & $\mathrm{T} 4$ & 3.60 & 0.55 & 3.75 & 0.71 \\
\hline & T5 & 4.20 & 0.45 & 4.13 & 0.64 \\
\hline \multirow[t]{5}{*}{ Logan } & $\mathrm{T} 1$ & 4.80 & 0.45 & 4.50 & 0.53 \\
\hline & $\mathrm{T} 2$ & 5.00 & 0.00 & 5.00 & 0.00 \\
\hline & T3 & 4.60 & 0.55 & 4.88 & 0.35 \\
\hline & $\mathrm{T} 4$ & 4.80 & 0.45 & 4.75 & 0.46 \\
\hline & T5 & 5.00 & 0.00 & 5.00 & 0.00 \\
\hline \multirow[t]{5}{*}{ Jack } & $\mathrm{T} 1$ & 5.00 & 0.00 & 5.00 & 0.00 \\
\hline & $\mathrm{T} 2$ & 5.00 & 0.00 & 5.00 & 0.00 \\
\hline & $\mathrm{T} 3$ & 5.00 & 0.00 & 5.00 & 0.00 \\
\hline & $\mathrm{T} 4$ & 5.00 & 0.00 & 5.00 & 0.00 \\
\hline & T5 & 5.00 & 0.00 & 5.00 & 0.00 \\
\hline
\end{tabular}

fluctuation). Furthermore, LE1 scores were typically higher than LE2 for each participant.

Furthermore, in relation to the first research question, an analysis of qualitative interview data highlighted emergent themes related to influencing factors on participants' LE fluctuations, including degree of experience (i.e., within fieldwork, coursework), reframed expectations (e.g., poor performance), personality effects (e.g., uncertainty, self-doubt), and increased knowledge and awareness (e.g., of selves as leaders and of industry aspects). Interestingly, when asked explicitly about their program, participants spoke to very few programmatic, curricular, or pedagogical components when reflecting on their own LE score fluctuations.

Degree of Experience. The most prevalent theme found as a perceived influencing factor on fluctuating LE scores was the participants' degree of experience gained during various times points over the program (i.e., upon entry, during the academic year, during summer) within various contexts (i.e., [not-for-credit] sport fieldwork, paid sport [or other] jobs, academic coursework). Brian noted that his LE2 scores (i.e., perception of skill to be a leader) rose the summer between his second and third years, to which he attributed to being "outside of the classroom," working with a professional soccer team, which enabled him to witness, apply, and "learn skills on the spot." Similarly, Ella's LE2 attributed to her job experiences, which affected her perception that she was "capable of doing a little bit more" than she originally believed. Conversely, Fadila attributed her fluctuating LE2 scores to gaining employment within work contexts where the sole focus was on supporting herself financially, which diminished leadership skill-building opportunities specifically related to the sport context. She noted, "[I didn't get to] practice and learn from experts, you know that have the skills." Both Molly and Ella attributed their high LE1 scores to having accumulated previous leadership experience (e.g., team captain roles, winning awards, work at McDonald's, course assignments) and to others verifying their leadership (e.g., Molly's mother telling her).

Reframed Expectations. A second theme found as a perceived influencing factor on fluctuating LE scores was participants' reframed expectations while progressing through the program. Steven perceived his fluctuating LE scores were due to the expectations he reframed in his second year, shifting from excitedly leaving his first-year courses, expecting to now "move on and learn about the stuff I want to learn," to encountering unmet expectations once engaged in these second-year courses, specific to what he thought he would learn within the classroom related to leadership. Adam and Brian described experiencing "reality checks," leading them to reframe their expectations, which they perceived impacted their LE score fluctuations, albeit differently. Adam's reality check was linked to performing poorly academically after his first year, which led to him being mandated to retake a (failed) core sport management course. Here, Adam noted his confidence rose while retaking the course, given "I knew what I was talking about ... I felt like I was ahead of everyone else.” Brian's reality check came after realizing that his first-year experience was more difficult than he initially expected, stating “it's like okay, this isn't what I thought it was ... there's a lot more failure than you thought there 
would be." Once Brian combined his reframed expectations with sport industry skill-building, his mean LE scores increased.

Personality Effects. A third theme found to be a perceived influencing factor on fluctuating LE scores was participants' various personality effects, where some expressed they experienced uncertainty, self-doubt, and diminished confidence during some part of the first 3 years of the undergraduate program. Logan attributed his LE score fluctuations during a 2-year period to having experienced uncertainty and his questioning whether he had chosen the right program of study. Upon developing interest in becoming an academic, he regained motivation, noting that the second year "was a big learning year in terms of what I actually want to do and making sure I can actually do it." Moreover, Ella's "second guessing" tendencies explained her LE score fluctuations, noting "even though I know that there's always room for improvement, I always worry that I'm not, I won't be good enough or I don't have the knowledge."

Increased Awareness and Knowledge. Participants described that acquiring knowledge and awareness over time about both themselves as leaders and the sport industry impacted their LE fluctuations. Dan attributed the large dip in mean LE1 scores to having taken the survey more seriously over time, given increased self-awareness, leading him to question "am I really a 5 in all aspects?; when, in reality, I'm 20-years old, 21 and there's still a lot of room for me to grow." Samantha linked her fluctuating LE scores to knowing more about both her own self as a leader and leadership, believing that as long as she could know and master an area well enough to then teach another she would then have the skills to lead. Samantha felt that "there's nothing that I know right now that I could just like get up and like, lead," which, in turn, influenced her low LE1 scores. Both Dan and Molly attributed their LE score fluctuations to having learned about the difficulties associated with securing such an industry role and what is necessary to be a leader in the sport industry. Furthermore, Bobby attributed fluctuating LE scores to his increased knowledge from sport organizational leader role models as a key piece to seeing himself as a leader over the longer term.

\section{Ego Development and Perceptions of LE}

To answer the second research question, data related to the structure and content of participants' level of ego development and associated stage-specific characteristics were connected to their perceptions of their LE score fluctuations. Findings related to participants' level of ego development are outlined, followed by qualitative data related to how participants connected their level of ego development to their LE scores.

Level of Ego Development. Regarding SCT results, at the third time point, when participants' ego development was measured, eight of 14 participants scored with a TPR (level of ego development) of 3/ 4 (i.e., Expert action logic), and six of 14 participants scored with a TPR of 4 (i.e., Achiever action logic). Viewing participants' SCT results from a developmental perspective over three time points, three distinct groups emerged, where a first group of four participants (i.e., Bobby, Molly, Brian, John) primarily measured and remained at a TPR of 3/4 (i.e., Expert action logic), having incurred no vertical development across three time points. Furthermore, a second group of four participants (i.e., Ella, Fadila, Katherine, Adam) initially measured with a TPR of 4 (i.e., Achiever action logic) and then measured with a TPR of 3/4 at the third time point, thereby indicating a regressive or fallback pattern (Livesay, 2015) across three time points. A third group of six participants (i.e., Logan, Dan, Steven, Samantha, James, Jack) initially measured with a TPR of 3/4 to then measure with a TPR of 4 (i.e., vertically developed from Expert to Achiever action logic) across three time points. See Table 3 for

Table 3 Outline of Ego Development Labels and Scores at Three Time Points

\begin{tabular}{|c|c|c|c|c|c|c|c|c|c|}
\hline Participant & $\begin{array}{l}\text { LDF } \\
\text { action } \\
\text { logic }\end{array}$ & $\begin{array}{c}\text { T1 ego } \\
\text { development } \\
\text { stage }\end{array}$ & $\begin{array}{c}\text { T1 } \\
\text { (TWS) }\end{array}$ & $\begin{array}{l}\text { LDF } \\
\text { action } \\
\text { logic }\end{array}$ & $\begin{array}{c}\text { T2 ego } \\
\text { development } \\
\text { stage }\end{array}$ & $\begin{array}{c}\text { T2 } \\
\text { (TWS) }\end{array}$ & $\begin{array}{c}\text { T3 ego } \\
\text { development } \\
\text { action logic }\end{array}$ & $\begin{array}{c}\text { T3 ego } \\
\text { development } \\
\text { stage }\end{array}$ & $\begin{array}{c}\text { T3 } \\
\text { (TWS) }\end{array}$ \\
\hline Bobby & Expert & $3 / 4$ & 209 & Expert & $3 / 4$ & 197 & Expert & $3 / 4$ & 204 \\
\hline Molly & Expert & $3 / 4$ & 209 & Expert & $3 / 4$ & 206 & Expert & $3 / 4$ & 202 \\
\hline Brian & Expert & $3 / 4$ & 207 & Expert & $3 / 4$ & 224 & Expert & $3 / 4$ & 209 \\
\hline John & Expert & $3 / 4$ & 205 & Expert & $3 / 4$ & 212 & Expert & $3 / 4$ & 199 \\
\hline Ella & Achiever & 4 & 228 & Expert & $3 / 4$ & 219 & Expert & $3 / 4$ & 212 \\
\hline Fadila & Expert & $3 / 4$ & 196 & Achiever & 4 & 223 & Expert & $3 / 4$ & 217 \\
\hline Katherine & Expert & $3 / 4$ & 213 & Achiever & 4 & 231 & Expert & $3 / 4$ & 214 \\
\hline Adam & Expert & $3 / 4$ & 205 & Achiever & 4 & 213 & Expert & 3 & 195 \\
\hline Logan & Expert & $3 / 4$ & 209 & Achiever & 4 & 222 & Achiever & 4 & 224 \\
\hline Dan & Expert & $3 / 4$ & 226 & Achiever & 4 & 229 & Achiever & 4 & 225 \\
\hline Steven & Expert & $3 / 4$ & 216 & Expert & $3 / 4$ & 211 & Achiever & 4 & 225 \\
\hline Samantha & Expert & $3 / 4$ & 203 & Expert & $3 / 4$ & 209 & Achiever & 4 & 203 \\
\hline James & Expert & $3 / 4$ & 201 & Expert & $3 / 4$ & 212 & Achiever & 4 & 227 \\
\hline Jack & Achiever & 4 & 224 & Expert & $3 / 4$ & 207 & Achiever & 4 & 228 \\
\hline
\end{tabular}

Note. Expert 3/4 interested in problem-solving; seeks causes; critical of self and others based on crafted logic; chooses efficiency over effectiveness; continuous improvement and perfection; accepts feedback only from objective craft masters; dogmatic; values decisions based on merit; sees contingencies, exceptions, wants to stand out, to be unique, sense of obligation to wider, internally consistent moral order; Achiever 4 Longer-term goals; future is vivid and important; welcomes behavioral feedback; effectiveness and results oriented; feels like an initiator, not a pawn; appreciates complexity and systems; seeks generalizable reasons for actions; seeks mutuality (and hierarchy) in relationships; feels guilt if does not meet own standards, blind to own achieving shadow, to the subjectivity behind objectivity; energized by practical dayto-day improvements based on self-chosen (nut not self-created) ethical system. Adapted from Personal and Organizational Transformations: Through Action Inquiry (4th ed., p. 43), by D. Fisher, D. Rooke, and W.R. Torbert. Boston, MA: Edge/Work. ( ) 2003. LDF= leadership development framework; TWS = total weighted score. 
participants' respective Total Weighted Score and TPR measures and commensurate LDF action logic.

\section{Making the Connection Between Ego Development and LE.} Prior to their respective interviews, each participant was sent their ego development and LE scores in addition to a description of specific LDF action logic characteristics at which they measured (i.e., Expert or Achiever). Those who measured at both Expert and Achiever action logics over time were sent both LDF action logic descriptions. Given Cook-Greuter's (2013) reminder that the meaning of discussed concepts "depends on the user and [their] relationship or view of a given concept" (p. 11), the structure (i.e., how participants framed their awareness when discussing concepts) and the content (i.e., topics, concepts) were connected to participants' responses about LE score fluctuations during their respective interviews.

Consistently Measuring at the Expert Action Logic. The first group of four participants (i.e., Bobby, Molly, Brian, John) measured with TPRs of 3/4 (i.e., Expert action logic) consistently over three time points. Though each of the four participants experienced LE score fluctuations occurring at variable times and for variable reasons, three themes emerged for how these participants' LDF action logics connected with their perceived LE score fluctuations. A first theme emerged where participants pointed to concrete evidence (e.g., perceived as either already evident or further needed) to explain their LE scores, including: academic (grade) improvements; previous leadership roles; gaining autonomy from living away from their parents for the first time; and skill application within sport-related contexts, regardless whether the participants explained their increasing or decreasing LE scores. For example, Molly explained her decreased LE1 scores, believing she needed further skill development, stating "I'm realizing that there's things I still need to gain in order to actually continue to be a leader."

A second theme emerged where three of four participants noted authority figures or credible others from their lives who explained their LE score fluctuations. For example, Brian referred to successful alumni who initially influenced high LE1 scores (i.e., at T1), explaining “you think there's such great alumni when you come in, the pathway is perceived to be easier just from the outside perception." Other participants referenced credible others, including parents, coaches, other organizational leaders, and supervisors, all of whom told them about their positive fit for being a leader, or, in Molly's case, "made me think I was a leader." A third theme emerged where participants explained their LE score fluctuations with a "taken-for-granted," assumptive tone about being a leader. For example, Molly stated 'I've never doubted for a second, especially just when other people tell you that sort of thing ... everything kind of sits in the back of your head, so I've never really doubted my abilities to be a leader." From his previous experience managing children as a camp counselor, John explained his LE1 scores through assuming future leadership, stating "I don't see why I wouldn't be as good as an adult leader, kind of thing."

Regressing from Achiever to Expert Action Logic. In the second group, four participants (i.e., Ella, Fadila, Katherine, Adam) measured with TPRs of either 3/4 or 4 (i.e., Expert or Achiever) over three time points, and all further measured with TPRs of 3/4 (i.e., Expert action logic) at the third time point, thereby showing a vertical regression or fallback pattern in scores over time. Of these four participants, three were women (i.e., Ella, Katherine, Fadila). Similar to the first group, LE score fluctuations occurred for these four participants at variable times and for variable reasons; however, a prevalent theme emerged in that these four participants exclusively associated their LE score fluctuations to experiences that impacted both their skill development and their self-confidence. Participants differed however, in the kinds of experiences and the actual impact they had on skill development and self-confidence outcomes (i.e., either increases or decreases in self-confidence). For example, Katherine attributed an increase in her LE2 scores from securing a job, stating "I felt pretty excited and confident at the end of second year." Furthermore, Ella attributed her LE scores to occasions when she took risks with jobs or was challenged by academic assignments, which impacted her perceptions of self. Alternatively, a difference existed between Katherine's LE1 and LE2 scores, to which she attributed to "second-guessing," asking herself questions, such as "do I know what I am doing? Am I in the right place right now?" Though she saw herself as capable and a "quick learner," she feared she lacked skills to be successful as a leader in the sport industry.

Furthermore, Adam attributed his LE score fluctuations to experiencing academic failure after his first year and that, while his LE1 decreased after his first year, his scores increased upon entering his second year. In this case, retaking a failed core sport management course allowed Adam to experience feeling "really good in seminar" and "more confident again." Moreover, Adam illuminated the relationship between his LE2 and LE1 scores from the perspective of skill development, as his LE2 scores were found to be consistently lower than his LE1 scores. Regarding such differences in LE scores, Adam stated a taken-for-granted assumption associated with other Expert participants, stating "it just makes sense that's the way it should be ... I just feel like it's easier to obtain a job than it is to actually develop the skills beforehand."

Vertically Developing to the Achiever Action Logic. Compared with the previous two groups of Expert participants, all six participants who vertically developed to the Achiever action logic explained their LE scores, with their responses demonstrating greater depth and nuance. Specifically, participants explained their LE score fluctuations by reflecting upon and using language that indicated more complex reasoning, rather than asserting with concrete, taken-for-granted language and intonation, as did Expert participants. Achiever participants connected to responses about their LE score fluctuations by demonstrating greater critical thinking, introspection, and self-assessment. Specifically, Achiever participants connected their LE fluctuations less to clichéd rationale and more to revelatory and nuanced thinking than did Expert participants, which included elements of contrast, critical self-examination, and questioning. That said, neither Achiever nor Expert participants explicitly referred to or connected with program components insofar as specifically facilitating their vertical development.

Three participants (Dan, James, and Samantha) connected their LE score fluctuations by expressing a more critically reflective tone regarding the subject of leadership. This tone was specific to how they believed degree of leadership knowledge, experience, and ability impacted their LE. First, Dan noted that his expectations toward leadership shifted over time, from entering the program and being like other students, "thinking they know everything" and desiring to become the general manager of a commercial sport team, to recognizing later that there were "certain things I need to work on and maybe taking the survey a bit more seriously in regards to how to, am I really a 5 [on the scale] in all aspects? When in reality, I'm 20-years old and there's still a lot of room for me to grow." James also questioned how he scored himself on LE survey items, noting "you have to be realistic ... . when I answer the question it was strongly agree, agree, neutral, and I always click agree just because I'm not saying strongly agree because I don't want to be over-confident." 
Samantha attributed her decreased LE2 scores at T4 to a lack of knowledge and experience. While Samantha believed she knew no specific areas well enough to lead, she felt that those areas for which she was passionate (i.e., finance) would help her cultivate leadership in the future, commenting " ... if I know that I could teach it to someone, then I would feel like I could lead it." Samantha further attributed her LE fluctuations to both her academic performance as well as how her diminished identification with professional sport, stating "when people think sport management, they think pro sport ... I honestly don't know that much about pro sport."

Of the six participants, Jack's LE scores reflected both no fluctuations through the entire time series and the highest LE scores of the entire sample (i.e., he self-scored 5.0 out of 5.0 through the entire time series). When asked what he attributed his LE scores to, Jack reflected with very little critical self-examination; rather, he connected his LE scores to his confidence in how he recognizes, understands, and adapts to "how I deal with somebody, based on the situation" and by understanding "their needs or based on how they are as a person," as well as being "confident in my actual technical skills." He also referred to having learned through setbacks and overcoming adversity over the long term, having developed a mindset of managing his emotions and "never getting too high or too low."

\section{Discussion}

The purpose of this study was to assess students' ego development and perceptions of LE across an undergraduate sport management program. The study was guided by two research questions: first, how do undergraduate students' perceptions of LE fluctuate over the course of their sport management academic program? And, second, how does level of ego development connect to students' perceptions of LE in a sport management academic program? The findings here outline that students' perceptions of self, related to their LE, changed and differed over time and were based on variable factors across participants. More specifically, each participant entered the program from high school with unique experiences, which shaped their beliefs about how they saw themselves as leaders. When explicitly asked, participants rarely expressed aspects of their academic program as factors that influenced their self-perceptions of leadership, which is inconsistent with previous sport management literature (Williams \& Parker, 2016). Furthermore, this highlights that critical development is an issue for these participants in this program, which falls short of the call for more transformative developmental opportunities within the sport management curriculum (Brown et al., 2018; Shaw et al., 2011).

In line with the first research question, findings outlined how participants perceived factors related to their LE score fluctuations. Moreover, LE1 scores were typically higher than LE2 for each participant, suggesting their perceptions of their ability to obtain a leadership position were higher than their perceptions of their skilled ability to be a leader. Participants' disclosure that the degree of practical experience impacted LE score fluctuations, which thereby shaped their efficacy, was not surprising (Bardou et al., 2003). However, participants noted "meaningful experiences" as factors related to the LE score fluctuations, thus highlighting the importance of adding thoughtful experiential education experiences throughout a degree program, not just in the final year of the program. This notion of thoughtful experiential opportunities highlights that this program lacked meaningful experiences that were directly linked to perceptions of leadership capability by these participants. Therefore, the ways in which experiential education is adopted to enhance critical development and assessment skills must be explored (Shaw et al., 2011). Furthermore, participants noted that reframing expectations around programmatic components served as both a positive and negative influence on LE scores. For example, upon reframing his expectations, Steven (Achiever) found his own developmental opportunities and could reframe his experience positively. These findings support previous research and suggest a continued exploration of students' met and unmet expectations experienced within their academic program (McClean et al., 2020).

Regarding the second research question, consistent with literature on university student samples (Adams \& Shea, 1979; Lambie et al., 2010), participants' TPR results measured at either the 3/4 or 4 (i.e., LDF Expert or Achiever action logics) - results that also align with the managerial samples measured (CookGreuter, 2004; Rooke \& Torbert, 2005). While all participants' LE profiles over four time points were found both to be unique and to fluctuate variably, qualitative themes from interview data revealed that Expert participants largely pointed to concrete evidence (i.e., skill development, grade improvements, credible others) when connecting to their LE score fluctuations-as developmentally expected-whereas Achievers connected to their LE score fluctuations by expressing appreciably more complex and nuanced perceptions, also as developmentally expected. Indeed, CookGreuter (2013b) noted that "certainty and knowing are regularly signs of a less seasoned ego at play, while embracing ambiguity and mystery are generally signs of more mature self-awareness" (p. 228). From these findings, three important contributions to new theoretical knowledge arise, including the presence of a majority of Experts within a cohort, the presence of a vertical regression or fallback pattern (Livesay, 2015) among participants, and the experience of Achiever participants.

\section{Majority Presence of Experts Within a Cohort}

When associated with findings (Cook-Greuter, 2004; Rooke \& Torbert, 2005) that most North American managers measure as Experts where, performance wise, these individuals wield leadership that is "below average corporate performance" (p. 68). This creates a compelling case to stimulate students' vertical development, especially given the increasingly volatile, uncertain, complex, and ambiguous (VUCA) environment managers are facing (Petrie, 2011; Joiners \& Josephs, 2008). Moreover, participants-regardless of their action logic measures over time-did not explicitly connect their vertical development to any components related to the academic program (i.e., related to program aspects, curriculum, pedagogy) within interviews. These findings raise questions and may suggest the value frequently espoused by university administrators that the program aids in undergraduate leadership development is misaligned with actual program practices. The findings suggest that a review of the undergraduate curriculum is needed to target specific courses and touchpoints where leadership and vertical development can be fostered.

\section{Presence of a Fallback Pattern Among Participants}

Second, four participants experienced fallback during the time series, which Livesay (2015) noted typically occurs "if the highest action logic of which you are capable isn't working and you seek access to that action logic, but you just can't get it" (p. 180). 
Specifically, these four participants experienced a disabling of complexity at the Achiever action logic, the highest vertical action logic at which they previously measured, such that they could not access regularly available Achiever-based capacities. Noting fallback and its associated causes as related to the findings in this study have important implications, particularly because three of the four participants who experienced fallback were women. Specifically, these three female participants connected to their LE scores through responses characterized by greater introspection than did their one male counterpart. All three participants associated their LE score fluctuations with various experiences that highlighted their skill development and the impact of such development on their selfconfidence, sourced possibly by beginning abilities to both introspect and critically analyze matters allowed by their Expert identity formation (Cook-Greuter, 2013a). Contrastingly, the one male participant associated his LE scores using an assumptive statement, "it just makes sense that's the way it should be." Hart and Mentkowski (1994) found that vertically developed female college graduates pursued leadership roles postgraduation to a greater degree than their less vertically developed counterparts. Therefore, it is compelling for female students in this case, especially within a male-dominated sport industry, to note vertical development patterns that represent both fallback and "spring forward" (Livesay, 2015). Knowing that these students' SCT results were representative of vertical fallback may help create more targeted teaching and learning strategies.

\section{The Experience of Achiever Participants}

Participants who vertically developed to the Achiever action logic discussed their perceptions of self-as-leaders in more conceptually complex and nuanced ways compared with Expert participants. Those who measured as Achievers were able to demonstrate an ability "to appreciate conceptual complexity" (Cook-Greuter, 2013a, p. 42), as they reflected on their experiences. Furthermore, perhaps having gone through periods of critical self-examination, participants gained a typical Achiever-based "measure of independence and self-authorship" (Cook-Greuter, 2013a, p. 41), which impacted LE scores. Achiever participants also began to push boundaries and be critical of information that they received and encountered, typical of such vertical development, as Achievers examine "what works and what is important to know" (CookGreuter, 2013a, p. 46). These Achievers' movement toward critical examination heralds an important developmental mark, as they enter an industry in which they (as leaders) must make thoughtful decisions. As such, if sport management educators in this case are truly concerned with critical thinking (Shaw et al., 2011) and leadership development, as marketed to potential students, they must be more aware of this map of consciousness and draw upon stage-related vertical developmental characteristics to target program initiatives toward Achiever (and beyond) action logics.

Using conditions offered by the sport management educational context (i.e., students find sport coursework personally salient; students are accustomed to working within team structures from sport experiences) advantageously, educators may support vertical development (McDonald \& Spence, 2016). Specifically, sport management educators may use these conditions alongside experiential education pedagogy to focus courses or projects on adaptive challenges that ultimately require students to draw upon more than their "current expertise, authoritative decision-making, standard operating procedures or culturally informed behaviors" (Heifetz, 2010, p. 73). When students are guided to reflect upon their work with adaptive challenges through experiential education, they take responsibility for their learning, which possibly initiates within them a testing and shifting of their assumptions, beliefs, priorities, habits, and even worldviews (Heifetz et al., 2009; McDonald \& Spence, 2016; Spence \& McDonald, 2015)precursors for vertical development.

For example, in facilitating students' vertical development from Expert to Achiever, educators are recommended to design activities in which students may heighten their awareness on the various assumptions they regularly make about both the learning activities and their teammates. Here, reflective engagement on activities is crucial in eliciting students' assumption-making (Spence et al., 2009; Spence \& McDonald, 2015). Furthermore, encouraging students to shift from autonomous "my-way-or-thehighway" problem-solving strategies to flexible, inquiry-based strategies focused on goal accomplishment when engaged with others on experiential learning activities is recommended. In doing so, students may shift their self-beliefs from being a superior, individual contributor to seeing themselves as working collaboratively as part of a team. The educator may create opportunities inherent within experiential learning activities to challenge Expert students to be better able to receive feedback, a capacity more typically found among Achievers. Such an experiential challenge may shift Experts developmentally from otherwise taking such feedback personally or dismissing it altogether while defending their perceived superior beliefs. The motive for Experts to develop may be personally salient, especially if they desire to achieve goals and improve their performance (Cook-Greuter, 2004).

Furthermore, in facilitating (Achiever) students' vertical development in such courses, educators are recommended to design activities in which students may both expand and deepen their views to accommodate a general shift in focus. Specifically, educators could promote moving such students toward "goal setting strategies to access and practice more systemic Individualist and Strategist assumptions and thinking, thereby aiding them in moving their focus from themselves and to the wider community" (Spence et al., 2009, p. 9). For example, instead of students solely viewing the benefits of achieving direct and measurable goals as a series of tasks and responsibilities, it is recommended that they understand experiential learning activities as more constitutive of a complex web of interdependent and collaborative relationships that often yield unintended, unpredictable, but yet ultimately important actions that positively affect project goals (Rooke \& Torbert, 2005). Specifically, such practices will heighten students' awareness of their own and others' worldviews (as differentiated yet equal), as well as highlighting the interdependence of such collective worldviews toward potential longerterm benefits to students and the success of experiential learning projects.

\section{Conclusion}

The results presented here provide a compelling argument that the theoretical frameworks of constructivist (ego) development theory and the LDF are useful in providing some explanation for why students' LE is "where it is." Specifically, participants' SCT measures and how they discussed their self-representations of how they made meaning and understood themselves within the world (CookGreuter, 2013b) were essential elements when connected to their perceptions of the LE score fluctuations. As such, this research has implications in that quantitatively assessing participants' ego development, simultaneous to qualitatively determining the nature and 
role of various pedagogical choices and critical incidents (i.e., meaningful experiential education) they perceived they incurred through their undergraduate program, helps faculty better understand how vertical development and various events may influence their LE.

From a program management perspective, such research has implications for how faculty may further consider curricular design in which vicarious experiences (e.g., challenging experiential education, use of self-reflection and feedback, peer developmental pacing) are strategically included to stimulate vertical development and critical thinking. Indeed, Spence and McDonald's (2015) finding is important here that "reflective activities seem key to eliciting students' cognition and awareness, confidence and self-efficacy, and behavioral capacity, all of which [lay] a platform to stimulate students' vertical development" (p. 308). For example, educators may consider how students can view successful leaders while they are engaged in experiential educational opportunities.

Specifically, students who measure as Experts may view experiential education components as more "relevant" and thus worthwhile if such components are delivered by "credible others" (e.g., industry professionals). Here educators are further advised to develop reflective practices targeted to meet the Expert-level student to assist them to "spring forward" (Livesay, 2015), relating to Spence's (2008) finding that "reflective practice is a critical aspect in students' (and leaders') learning from experience and in their vertical development" (p. 12). Thus, it is important to assess how case study projects and hands-on application of theoretical material are delivered - and, specifically, by whom - to ensure that Expert students derive positive and even catalyzing vertical developmental impacts, given that the majority of students developmentally measure at this action logic.

Furthermore, when developing self-reflection activities for internship curricula or other experientially based projectsprocesses and activities that Spence and McDonald (2015) note as helpful in stimulating vertical development-it is important for educators to recognize that students will relate to and experience these activities and their components differently, based upon their vertical development. For example, the Experts in this study would likely approach activities with both (undo) critical and dismissive thinking, coming from a self-interested "what is in it for me?" perspective. Understanding the progressive vertical developmental pathway from "relativizing self-interest, to thinking collectively, to an even more complex capacity of holding simultaneous perspectives, culminating in independent thinking and self-authorship" (Spence \& McDonald, 2015, p. 308), educators are advised to consciously communicate both the purpose and outcomes of the reflection and how reflection connects to Expert students as unique and separate from other students given their worldview. This reflection is a powerful aid to assist Expert students toward and along this vertical developmental pathway.

Moreover, when developing and facilitating experiential education activities, educators are advised to allow Expert students to practice skill development, while consciously connecting them to develop greater flexibility around inquiry, so as to deepen their introspective capacity (Spence et al., 2009). Specifically, faculty could craft discussions around these experientially based assignments, asking open-ended questions with specific Expert characteristics in mind, thereby heightening students' awareness on the assumptions they regularly make so they may develop alternative beliefs from the next (Achiever) vertical level of development (Spence et al., 2009).
As noted earlier, study participants' SCT scores reflect findings limited to only two levels of ego development (i.e., Expert and Achiever action logics) among the entire vertical development spectrum. The mixed-method case study design and the qualitative interviews, however, provided a helpful framework to probe participants' specific action logic, insofar as connecting their language to specific Expert- and Achiever-based cognitive, emotional, and behavioral characteristics and to their perceptions of their LE score fluctuations. Furthermore, the measure of perceptions of self, related to leadership vis-à-vis LE1 and LE2 items were adapted from previous measures of efficacy in other contexts, which may benefit from future scale development assessments. As noted, a participant commented he did not take the survey as seriously at first, thus highlighting the importance of a longitudinal mixed-method study to clarify points and allow for participant development and commitment to occur. Although not a focus in this study, future research should examine the LE scale utility in sport management education contexts.

The theoretical link between ego development and LE warrants continued exploration. Expert and Achiever participants within the current sample and their behavioral, cognitive, and emotional characteristics exhibited in relation to LE scores may be further extrapolated during the upper years of their degree programs. For example, educators are recommended to seek ways to structure learning so that students solve personally salient, adaptive challenges alongside using reflective practice to test their assumptions and beliefs about themselves, others, and the elements involved in such learning. Explicitly mapping learning objects against key stage-specific action logic characteristics may also articulate students' learning and give them a map of the terrain of vertical development so they may more consciously follow their own development. Given the deepened focus on development and preparedness through experiential education in both the third (junior) and fourth (senior) years of a degree program, the influence of ego development on participants' LE may highlight unique nuances not captured in the present study. Future research may emphasize the role of ego development for educators involved in curriculum development and timely interventions at specific touchpoints through a 4-year undergraduate degree program so they may better prepare students by both stimulating their vertical development and enhancing their perceived LE as they exit university and start their careers.

\section{Acknowledgment}

The data within this manuscript were collected as a result of a Brock University Chancellor's Chair for Teaching Excellence grant.

\section{References}

Adams, G.R., \& Shea, J.A. (1979). The relationship between identity status, locus of control, and ego development. Journal of Youth and Adolescence, 8(1), 81-89. PubMed ID: 24317648 https://doi.org/10. 1007/BF02139142.

Bandura, A. (1977). Social learning theory. General Learning Press.

Bardou, K.J., Bryne, S.M., Pasternak, V.S., Perez, N.C., \& Rainey, A.L. (2003). Self-efficacy and student leaders: The effects of gender, previous leadership experiences and institutional environment. Journal of the Student Personnel Association at Indiana University, $33-48$. 
Brown, C., Willett, J., Goldfine, R., \& Goldfine, B. (2018). Sport management internships: Recommendations for improving upon experiential learning. Journal of Hospitality, Leisure, Sport \& Tourism Education, 22, 75-81. https://doi.org/10.1016/j.jhlste.2018.02.001.

Cambridge (2020). Cambridge Advanced Learner's Dictionary \& Thesaurus. Cambridge University Press.

Cook-Greuter, S.R. (1994). Rare forms of self-understanding in mature adults. In M. E. Miller \& S. R. Cook-Greuter (Eds.), Transcendence and mature thought in adulthood: The further reaches of adult development (pp. 119-146). Rowman \& Littlefield.

Cook-Greuter, S.R. (2004). Making the case for a developmental perspective. Industrial and Commercial Training, 36(7), 275-281.

Cook-Greuter, S.R. (2013a). Nine levels of increasing embrace in ego development: A full-spectrum theory of vertical growth and meaning making. http://www.cook-greuter.com/Cook-Greuter\%209\%20levels\% 20paper\%20new\%201.1\%2714\%2097p\%5B1\%5D.pdf.

Cook-Greuter, S.R. (2013b). Assumptions vs. assertions: Separating hypotheses from truth in the integral community. Journal of Integral Theory and Practice, 8(3-4), 227-236.

Cook-Greuter, S.R., \& Soulen, J. (2007). The developmental perspective in integral counseling. Counseling and Values, 51(3), 180-192. https://doi.org/10.1002/j.2161-007X.2007.tb00077.x

Creswell, J.W. (2009). Research design: Qualitative, quantitative, and mixed methods approaches (3rd ed.). Sage Publications.

Creswell, J.W., Plano Clark, V.L., Gutmann, M.L., \& Hanson, W.E. (2003). Advanced mixed methods research designs. In A.Tashakkori \& C. Teddlie (Eds.), Handbook of mixed methods in social and behavioral research (pp. 209-240). Sage.

Cunningham, G.B. (2014). Interdependence, mutuality, and collective action in sport. Journal of Sport Management, 28(1), 1-7. https:// doi.org/10.1123/jsm.2013-0152

Cunningham, G.B., Bruening, J., Sartore, M.L., Sagas, M., \& Fink, J.S. (2005). The application of social cognitive career theory to sport and leisure career choices. Journal of Career Development, 32(2), 122138. https://doi.org/10.1177/0894845305279164

DeLuca, J.R., \& Braunstein-Minkove, J. (2016). An evaluation of sport management student preparedness: Recommendations for adapting curriculum to meet industry needs. Sport Management Education Journal, 10(1), 1-12. https://doi.org/10.1123/SMEJ.2014-0027

DeWitz, S.J., Woolsey, M.L., \& Walsh, W.B. (2009). College student retention: An exploration of the relationship between self-efficacy beliefs and purpose in life among college students. Journal of College Student Development, 50(1), 19-34. https://doi.org/10. 1353/csd.0.0049

Eisenhardt, K.M. (1989). Building theories from case study research. Academy of Management Review, 14(4), 532-550.

Fisher, D., Rooke, D., \& Torbert, W.R. (2003). Personal and organizational transformations: Through action inquiry. EdgelWork.

Hannah, S.T., Avolio, B.J., Luthans, F., \& Harms, P. 2008. Leadership efficacy: Review and future directions. The Leadership Quarterly, 19 (Yearly Review of Leadership), 669-692.

Hart, J., \& Mentkowski, M. (1994). The development of the whole person: Women's ego development from entrance to five years after college. Paper presented at the annual meeting of the American Educational Research Association, New Orleans. Alverno College Institute.

Heifetz, R., Grashow, A., \& Linsky, M. (2009). The practice of adaptive leadership: Tools and tactics for changing your organization and the world. Harvard Business.

Heifetz, R.A. (2010). Adaptive work. The Journal Kansas Leadership Centre, Spring, 72-77.

Hy, L.X., \& Loevinger, J. (1996). Measuring ego development (2nd ed.). Lawrence Erlbaum Associates.
Joiners, B., \& Josephs, S. (2008). Leadership agility: Five levels of mastery for anticipating and initiating change. Jossey-Bass.

Lambie, G.W., Hagedorn, W.B., \& Ieva, K.P. (2010). Social-cognitive development, ethical and legal knowledge, and ethical decision making of counselor education students. Counselor Education and Supervision, 49(4), 228-246. https://doi.org/10.1002/j.1556-6978.2010.tb00100.x

Livesay, V.T. (2015). One step back, two steps forward: Fallback in human and leadership development. Journal of Leadership, Accountability and Ethics, 12(4), 173-189.

Loevinger, J. (1979). The idea of the ego. The Counseling Psychologist, 8(2), 3-5. https://doi.org/10.1177/001100007900800202

Loevinger, J. (1998). Technical foundations for measuring ego development: The Washington University Sentence Completion Test. Lawrence Erlbaum Associates.

Manners, J., \& Durkin, K. (2001). A critical review of the validity of ego development theory and its measurement. Journal of Personality Assessment, 77(3), 541-567.

McClean, C., Odio, M.A., \& Kerwin, S. (2020). Exploring the influence of stimulus events: A case study of undergraduate student internships. Sport Management Education Journal, 1, 1-13.

McCormick, M.J., Tanguma, J., \& López-Forment, A.S. (2002). Extending self-efficacy theory to leadership: A review and empirical test. Journal of Leadership Education, 1(2), 34-49. https://doi.org/10. 12806/V1/I2/TF1

McCrae, R.R., \& Costa, P.T. (1980). Openness to experience and ego level in Loevinger's sentence completion test: Dispositional contributions to developmental models of personality. Journal of Personality and Social Psychology, 39(6), 1179-1190. https://doi.org/10.1037/ h0077727

McDonald, M.A., \& Spence, K. (2016). Experiential learning: Impacting student lateral and vertical development. Sport Management Education Journal, 10(2), 140-147. https://doi.org/10.1123/smej.2015-0026

Patton, M.Q. (2014). Qualitative research \& evaluation methods: Integrating theory and practice. SAGE publications.

Petrie, N. (2011). Future trends in leadership development (A white paper). Centre for Creative Leadership.

Quigley, N.R. (2013). A longitudinal, multilevel study of leadership efficacy development in MBA teams. Academy of Management Learning \& Education, 12(4), 579-602. https://doi.org/10.5465/ amle.2011.0524

Rooke D., \& Torbert, W.R. (2005). Seven transformations of leadership. Harvard Business Review, 83(4), 67-76.

Shaw, S., \& Frisby, W. (2006). Can gender equity be more equitable? Promoting an alternative frame for sport management research, education, and practice. Journal of Sport Management, 20(4), 483-509. https://doi.org/10.1123/jsm.20.4.483

Shaw, S., Wolfe, R., \& Frisby, W. (2011). A critical management studies approach to sport management education: Insights, challenges and opportunities. Sport Management Education Journal, 5(1), 1-13. https://doi.org/10.1123/smej.5.1.1

Spence, K.K. (2008). Applying Wilber's All Quadrant, All Level (AQAL) Integral approach to sport management internship curricula. International Journal of Sport Management and Marketing, 4(2/3), 295-315. https://doi.org/10.1504/IJSMM.2008.018653

Spence, K.K., Hess, D.G., McDonald, M., \& Sheehan, B.J. (2009). Designing experiential learning curricula to develop future sport leaders. Sport Management Education Journal, 3(1), 1-25. https:// doi.org/10.1123/smej.3.1.1

Spence, K.K., \& McDonald, M.A. (2015). Assessing vertical development in experiential learning curriculum. Journal of Experiential Education, 38(3), 296-312. https://doi.org/10. 1177/1053825915571749 
Williams, J., \& Parker, H.M. (2016). Integration of experiential learning and leadership development in a sport management classroom. Sport Management Education Journal, 10(1), 54-63. https://doi.org/10. 1123/SMEJ.2015-0012
Zakus, D.H., Malloy, D.C., \& Edwards, A. (2007). Critical and ethical thinking in sport management: Philosophical rationales and examples of methods. Sport Management Review, 10(2), 133-158. https://doi. org/10.1016/S1441-3523(07)70008-6 


\section{Appendix: Interview Guide}

1. Tell me about any challenges that you may have experienced in the Sport Management program.

a. Please explain how you dealt with such challenges.

b. Can you explain how (if at all) these challenges changed you in any way?

2. Do you remember the time period just before this challenge occurred? Specifically, was there something else that occurred in your life that contributed to this challenge coming to mind?

3. How do you believe you have developed as a person since entering university, if at all?

a. What do you think needs to happen for you to develop into the future employee/person you want to be?

4. Do you engage in any activities that help you develop professionally or personally?

Note for interviewer. Personal development can be physical, cognitivelemotional, and/or spiritual.

a. What are those activities, if any?

b. For how long have you been engaged in such activities?

c. How have these activities affected you professionally or personally?
5. Based on the reading that was sent to you and your ego development rating, your ratings for ego development have stayed at [insert description] then went to [insert description]; would you agree with this stage of development for yourself? Why or why not?

6. From your survey responses [insert description of scores], it appears your level of LE (so, your belief in your ability to be a leader in the sport industry) was relatively [insert descriptor]. Can you think of experiences/life situations/program components that may have impacted this perception of capability in a leadership position in the sport industry? Can you explain why these experiences may have shaped your LE?

7. Can you explain what happens to you (cognitively, behaviourally, thinking) when you see others perform well, particularly in leadership-related contexts?

8. Can you think of a time where you challenged other people's point of views within a group?

a. Can you think of a time when you made a mistake? How did you handle that mistake?

b. Can you think of a time when you shared your opinion on improvements that could be made to an assignment or task? 